\title{
Deep Delineation Evaluation Drilling Methods, Jwaneng Mine, Botswana.
}

\author{
F.T. McKinlay ${ }^{1}$, Dr. M. Roberts ${ }^{2}$ \\ 1) Debswana, Jwaneng, Botswana, (tmckinlay@ debswana.bw), \\ 2) Debswana, Gaborone, Botswana, (mroberts@ debswana.bw)
}

\section{Introduction}

Anticipated future mining options at Jwaneng seek to exploit ore to depths of $1000 \mathrm{~m}$ and beyond. In order to support future mining studies and investment option selection, successful evaluation of geoscientific properties (geological and geotechnical) of the kimberlites at depth are required. Solutions include drilling to intersect the kimberlite ore bodies at depth in the 850 to 1,000 meter zone mining zone and beyond. To date the geological model has been developed with high confidence to 850 meter depth and to 1,000 meters depth with medium confidence. A second option includes developing an underground drift from surface to intercept the kimberlites at depth followed by underground drilling and bulk sampling. The latter option will not be reviewed in this document.

There are several methodologies of drilling from surface that can be considered. They include the following; wireline core drilling with conventional drill sizes (PQ and HQ core sizes); rotary or percussion drilling from surface to a specified depth followed by core drilling; core drilling using larger SK size core drilling equipment producing core sizes of $100 \mathrm{~mm}$ and $80 \mathrm{~mm}$; drilling from surface using down hole directional drilling equipment to a specified depth followed by wireline core drilling.

Key requirements for successful drilling solutions include a high level of drilling accuracy and recovery of good quality core samples for geotechnical testing and analysis. The three Jwaneng kimberlites (North, Center and South) are composed mainly of volcanoclastic kimberlite (VK), with the North pipe containing a central core of pyroclastic kimberlite (PK). They are hosted within a sequence of quartzitic shales to 500 meters depth underlain by silicified dolomite to a depth beyond 1,000 meters. Developing an accurate method of drilling from surface is critical in order to evaluate individual mining blocks within the kimberlite ore bodies. Geological and geotechnical information is required from evaluation drilling to inform optimized future mine design. The Jwaneng Mine currently is an open pit approximately 400 meters depth. The open pit has been planned to extend to approximately 836 meters depth which defines the bottom of the Cut 9 mining shell. The post Cut 9 zone is that which is defined in the 850 to 1,000 meters depth. Future mining options include consideration for Cut 10 open pit mining or to develop an underground mine.

There are several challenges to drill the kimberlite pipes from surface successfully. Drill rods tend to deviate with increased depth and therefore can miss the planned target. The Jwaneng VK units are typically soft with abundant clay content that cause excessive drill cuttings. A significant percentage of the clay is Nasmectite variety which has properties that cause it to swell when exposed to water. This typically increases resistance and torque on the drill rods and leads to common hole failures at depth. In order to overcome the challenges presented by the clay-rich kimberlite drilling methods need to be developed to enable the drill 
cuttings to be lifted out of the deep bore holes efficiently and effectively. Effective management of drill fluid specific gravity is important to ensure that the cuttings are lifted from depth and cleared effectively from the bore hole. Drill additives must be used to supplement the circulating fluids to inhibit or prevent the clay-rich kimberlite from swelling and causing the above mentioned drill failures. Specific chemicals have been developed by various supply companies to reduce torque on the drill rods, to minimize water contact with freshly drilled kimberlite and to build a sturdy filter cake that will stabilize the borehole walls. Strict management of the use of chemical additives while drilling kimberlite intersections is critical to ensure that their designs are effective.

Several methods of drilling deep evaluation holes have been recently tested at Jwaneng to overcome the challenges. Specially designed large diameter drill rods that resist shearing due to increased torque have been successful. This refers to the above mentioned SK drill equipment which produces larger core sizes than conventional drill systems. Top drive drills with appropriate hydraulic pullback capacity to overcome deep drill systems have been utilized. The required pullback power of the drilling system can be determined by the calculating the weight of the drill string plus the bottom hole assembly. Added to this will be the resistance of friction caused by the drill rods resting on the bottom of an inclined drill hole and the pressure that the rock formations exert on the drill string. The clay-rich kimberlite tends to swell and attempts to close the borehole diameter when drilled at depth due to deep confining pressures. Testing large diameter drill holes of $162 \mathrm{~mm}$ in diameter have been rotary (tricone) drilled from surface to 900 meters depth followed by large diameter (100mm core size) core drilling. The large diameter core system provides the ability to reduce to a smaller core size to overcome increased torque built up on the rods at depth, and act as casing for the smaller diameter drill systems. The large diameter core systems also provide the ability to utilize larger drill bit sizes (oversize) where the annular space between the drill rods and the borehole wall is proportionally greater than smaller conventional drill sizes and as a result allows drill cuttings to be cleared more effectively. This then allows less chance of cuttings remaining in the hole binding the drill rods and bottom hole assembly.

Accuracy of the planned drill path remains a priority. However rotary drilling was found to deviate significantly away from the drill planned path. The planned inclination of the rotary system dropped by up to 10 degrees beyond the end of the casing. Casing was install to depths up to 120 meters. During testing the rotary drilling continued to 400 meters depth and beyond. It was found that deviation of the drill rods increased beyond acceptable limits past 400 meters depth. Relatively severe directional correction curves in the drill hole create additional challenges as the hole is deepened. When used correctly down hole directionally controlled drill motors (MWD-measure while drilling) were successful to correct the deviated drill path back to the planned target. The experience and skill of the drill operator is also critical for success to prevent additional challenges down the hole.

Appropriate chemicals, as noted above, have also been successfully demonstrated to inhibit the reactive clay-rich kimberlite from swelling (which increases torque on the drill rods). It is important to continue to circulate the designed chemical mixture in the hole especially when intersecting kimberlite. If left unattended the chemicals will break down over time and become less effective in their ability to stabilize the hole and prevent the clay-rich kimberlite from swelling. A majority of the chemicals are biodegradable and will break down if not continually refreshed. It was also found that raw water used to make the drilling fluid mixture could provide additional conditions which could contribute reduced effectiveness of the chemical additives if left unattended. Successful use of drilling additives is also achieved by utilizing technical experts with knowledge of chemicals developed to optimize clay-rich kimberlite drilling. 
Technical experts provide knowledge gained from a host of projects. Establishing a dedicated drill-site resource to monitor and maintain drilling fluid composition is also a key to success. Geological structures intersected while drilling can add or remove water from the fluid system upsetting the balance proportions of chemicals. A dedicated "mud manager" will ensure the fluid mixtures are maintained in the correct balance. External consultants from chemical supply companies or those who specialize in drilling fluids add significant value to train personnel to become the in-house on-site mud manager to ensure that chemicals are used properly. Dedicated drill fluid management will significantly increase the ability to recover good quality kimberlite core samples and advance the drill depth through difficult conditions.

The limits of conventional PQ/HQ coring have also been tested and demonstrate the potential to supplement the more expensive but highly accurate directional drilling methods. Small diameter conventional wireline drilling was planned to intersect the kimberlite at a designed pierce point, recover good quality kimberlite core and drill through the kimberlite pipe to intersect a second kimberlite pierce point. PQ size core was drilled to 931 meters depth followed by HQ size core drilled to 1,184 meters depth. VK kimberlite was intersected at 996 meters depth, and 184 meters of good quality core was recovered. While success was achieved by recovering a significant intersection of good quality kimberlite core the hole was stopped due to increased pressures and torque exerted on the rods and bottom hole assembly. Only one kimberlite pierce point was intersected. Minimal deviation of the drill path was observed to approximately 800 meters depth after which the hole swung increasingly to the right as the hole advanced beyond this point. The initial planned point of intersection was not achieved accurately. Therefore while small conventional size core drilling will provide important information to obtain geological and geotechnical information to date has not demonstrated the ability to drill at depth with accuracy without the use of a down hole directional motor.

Continued testing of deep drilling methods (core and LDD) are currently underway in order to test the technical ability to develop integrated geoscience models through drilling methods alone in hole lengths in excess of $1500 \mathrm{~m}$ (core) and 700m (LDD). Technical specifications for deep drill systems have been established for future kimberlite evaluation drill projects at Jwaneng mine. International consultants have been involved to assist in the development of these technical requirements. They have experience in various types of drill programs and geological conditions operating in several countries. Inclusion of the external experts to help design future drill programs has added considerable value to Jwaneng kimberlite drill projects. Knowledge and training from external technical experts to in-site project management teams has added considerable value to the Jwaneng projects to design future drill programs. 